\title{
Ethyl Acetate Fraction from Leandra dasytricha (A. Gray) Cong. Leaves Promotes Vasodilatation and Reduces Blood Pressure in Normotensive and Hypertensive Rats
}

\author{
Rita de Cassia Vilhena da Silva, ${ }^{1}$ Luísa Nathália Bolda Mariano, ${ }^{1}$ Eleine Renata Bidinha, ${ }^{1}$ \\ Camila Leandra Bueno de Almeida, ${ }^{1}$ Valdir Cechinel-Filho, ${ }^{1}$ \\ Vanessa Samudio Santos Zanuncio, ${ }^{2}$ Denise Brentan Silva, ${ }^{2}$ \\ Arquimedes Gasparotto Junior ${ }_{(D,}{ }^{3}$ and Priscila de Souza ${ }^{1}{ }^{1}$ \\ ${ }^{1}$ Postgraduate Program in Pharmaceutical Sciences, Nucleus of Chemical-Pharmaceutical Investigations, \\ University of Vale do Itajaí, Itajaí, Brazil \\ ${ }^{2}$ Laboratory of Natural Products and Mass Spectrometry, Faculty of Pharmaceutical Sciences, Food and Nutrition, \\ Federal University of Mato Grosso do Sul, Campo Grande, MatoGrosso do Sul, Brazil \\ ${ }^{3}$ Laboratory of Cardiovascular Pharmacology, Faculty of Health Sciences, Federal University of Grande Dourados, Dourados, \\ MatoGrosso do Sul, Brazil
}

Correspondence should be addressed to Priscila de Souza; priscilasouza_rc@yahoo.com.br

Received 5 September 2021; Accepted 28 October 2021; Published 15 November 2021

Academic Editor: Eliana Rodrigues

Copyright (c) 2021 Rita de Cassia Vilhena da Silva et al. This is an open access article distributed under the Creative Commons Attribution License, which permits unrestricted use, distribution, and reproduction in any medium, provided the original work is properly cited.

\begin{abstract}
Leandra dasytricha (A. Gray) Cong. is widely distributed in the south of Brazil and is commonly used for cardiovascular and kidney ailments. For this study, we used male Wistar normotensive rats (NTRs) and spontaneously hypertensive rats (SHRs) to verify the effects of the ethyl acetate fraction (EAF) obtained from L. dasytricha leaves on isolated aorta relaxation and in the arterial blood pressure. The EAF was analyzed by LC-DAD-MS, and several components were annotated, including hydrolysable tannins, triterpenes, and $O$ - and $C$-glycosylated dihydrochalcones, such as the most intense ion peak relative to $C$-hexosyl phloretin (nothofagin; compound number 13). The EAF caused a concentration and endothelium-dependent relaxation of the aorta in both NTRs and SHRs. This effect was abolished in the endothelium-denuded aorta. L-NAME, a nonselective nitric oxide synthase inhibitor, and ODQ, a soluble guanylate cyclase inhibitor, entirely blocked the EAF-induced relaxation. The presence of a muscarinic receptor antagonist or a cyclooxygenase inhibitor did not alter the EAF's effectiveness in relaxing the aorta. The preincubation with tetraethylammonium, a $\mathrm{Ca}^{2+}$-activated $\mathrm{K}^{+}$channel blocker, and with 4-aminopyridine, a voltage-dependent $\mathrm{K}^{+}$channel blocker, significantly interfered with the EAF's relaxation. However, the incubation with glibenclamide, an ATPsensitive $\mathrm{K}^{+}$channel blocker, and barium chloride, an inward-rectifier $\mathrm{K}^{+}$channel blocker, did not interfere with the EAF-induced relaxation. The EAF treatment also caused a dose-dependent decrease in the mean arterial pressure, systolic arterial pressure, and diastolic arterial pressure of both NTRs and SHRs, without significantly interfering with heart rate values. In conclusion, this study demonstrated the EAF-induced vasorelaxant and hypotensive actions, primarily dependent on the endothelium function and mainly with the participation of the nitric oxide and $\mathrm{Ca}^{2+}$-activated and voltage-dependent $\mathrm{K}^{+}$channels.
\end{abstract}

\section{Introduction}

According to data from the American Heart Association (AHA), heart diseases are the leading causes of death globally. In 2019, nearly 18.6 million people worldwide died from cardiovascular diseases (CVDs) [1], hypertension being the most common risk factor [2]. The pathogenesis of hypertension involves many factors, and the treatment requires a healthy lifestyle and multiple therapies in a large majority of patients. The main objective in the treatment of 
hypertension is to prevent the occurrence of damage to the blood vessels and heart caused by sustained high blood pressure levels. A slight reduction in systolic blood pressure is enough to decrease mortality levels and cardiovascular risks [3]. There are several classes of antihypertensive drugs; however, the failure to effectively control blood pressure can occur for several reasons, including suboptimal treatment and disease progression, with nonadherence to the treatment being responsible for 50 to $80 \%$ of unsatisfactory pressure reduction [4-6]. For these reasons, cardiovascular disease risks remain increased in hypertensive patients. Alternative approaches, such as herbal preparations with higher efficacy and lower toxicity, are sought to improve treatments and are also used to prevent cardiovascular complications [7].

Leandra dasytricha (A. Gray) Cong., popularly known as "pixirica," belongs to the Melastomataceae family, which is widely distributed in the south of Brazil [8]. In addition to L. dasytricha, other species of Leandra have also shown pharmacological effects. L. lacunosa had a hypoglycemic effect in alloxan-induced diabetes in rats, and L. chaetodon revealed an antifungal activity $[9,10]$. Recently, the ethyl acetate fraction isolated from $L$. dasytricha leaves exhibited the ability to increase the urine volume when orally given to rats. Its isolated compound nothofagin presented diuretic, natriuretic, and renal protective effects in both normotensive and hypertensive rats $[11,12]$. In addition, nothofagin induced endothelium-dependent vasodilation in renal arteries [13].

Although $L$. dasytricha is commonly used for cardiovascular and kidney ailments $[11,12]$, studies with its preparations are still scarce. Based on the premise of developing new therapeutic alternatives for the treatment of cardiovascular diseases, this study extends the investigations from a semipurified fraction obtained from the leaves of L. dasytricha and demonstrates the chemical profile of this preparation. In this context, it became interesting to evaluate the possible vasodilator and hypotensive properties in both normotensive and hypertensive rats. Spontaneously hypertensive rats (SHRs) are developed by selective breeding of Wistar Kyoto rats for high blood pressure to develop hypertension [14]; they are considered a suitable animal model of essential or primary human hypertension and have been widely used to study cardiovascular diseases [15].

\section{Materials and Methods}

2.1. Drugs and Chemicals. Atropine, acetylcholine chloride (ACh), indomethacin, $\mathrm{N} \omega$-nitro-l-arginine methyl ester (LNAME), H-[1,2,3] oxadiazolo[4,3-alpha]quinoxalin (ODQ), phenylephrine hydrochloride (PE), tetraethylammonium (TEA), glibenclamide (GLI), 4-aminopyridine (4-AP), barium chloride $\left(\mathrm{BaCl}_{2}\right)$, and all salts used to prepare the Krebs solution were purchased from Merck \& Co. (Kenilworth, New Jersey, USA).

2.2. Phytochemical Procedures. The leaves of Leandra dasytricha (A. Gray) Cong. were collected from Camboriú,
SC, Brazil (May 2014). Prof. Dr. Oscar Iza (UNIVALI) identified the plant species, and a voucher specimen has been deposited in the Barbosa Rodrigues Herbarium under number VCF 145. The preparation of the extract and the fractions were described by de Almeida et al. [11]. Briefly, fresh leaves of $L$. dasytricha were macerated at room temperature in methanol for 7 days. The ethyl acetate fraction (EAF) was obtained from the partition of the crude methanolic extract of $L$. dasytricha leaves by adding the ethyl acetate solvent.

2.3. LC-DAD-MS Analysis of L. dasytricha. The ethyl acetate fraction (EAF) of $L$. dasytricha leaves was solubilized in methanol and water $(7: 3, \mathrm{v} / \mathrm{v})$ at a concentration of $2 \mathrm{mg} /$ $\mathrm{mL}$. Subsequently, this solution was filtered through a syringe filter $\left(0.22 \mu \mathrm{M}\right.$ pore, membrane PTFE, Millex ${ }^{8}$ filters $)$ and analyzed by liquid chromatography coupled to a diode array detector and mass spectrometer (LC-DAD-MS) using a Kinetex C-18 column $(2.6 \mu \mathrm{m}, 150 \times 2.2 \mathrm{~mm}$, Phenomenex) with a precolumn of the same stationary phase material. The mass spectrometer MicrOTOF-Q III (Bruker Daltonics) was provided with an electrospray ionization source and quadrupole-time-of-flight analyzers. The elution gradient profile was the same reported by Tolouei et al. [16]. The mobile phase was composed by acetonitrile and ultrapure water with $0.1 \%$ formic acid. The oven temperature was $50^{\circ} \mathrm{C}$, and the volume of injection was $2 \mu \mathrm{L}$.

The analyses were obtained by positive and negative ion modes $(m / z 120-1200)$. Additionally, the compounds were monitored at wavelengths ranging from 240 to $800 \mathrm{~nm}$. The annotation of the constituents from EAF was based on MS data (accurate mass and the ion fragmentation pathway) and UV data compared to data reported in the literature. The molecular formula of each compound was determined based on the mass errors within $\pm 5 \mathrm{ppm}$ and mSigma below 30 . The authentic standards (gallic acid, catechin, and ellagic acid) were injected to confirm the identification of some metabolites.

2.4. Animals. Male normotensive Wistar rats (NTRs) and male spontaneously hypertensive rats (SHRs), twelve weeks old (250-300 g), provided by Universidade do Vale do Itajaí (UNIVALI), were kept at a constant temperature $\left(22 \pm{ }^{\circ} \mathrm{C}\right)$ under a $12 \mathrm{~h}$ light $/ 12 \mathrm{~h}$ dark cycle. The animal had free access to water and feed. The experiments were approved by the Ethical Committee for the Care and Use of animals of UNIVALI (authorization $n^{\circ}$. 045/16 and 014/21), which followed the guidelines of the Brazilian National Council for Control of Animal Experimentation.

2.5. Isolation, Preparation of Rat Aorta, and Vascular Reactivity Studies. The thoracic aorta was isolated from male NTR and male SHR as previously described by Da Silva et al. [17].Briefly, the thoracic aorta was removed under anesthesia, cleaned of fat and connective tissue, and cut into rings (3-4 mm length). They were kept in organ baths containing Krebs solution (composition in $\mathrm{mM}: \mathrm{NaCl} 115.3, \mathrm{KCl} 4.9$, 
$\mathrm{CaCl}_{2} \cdot 2 \mathrm{H}_{2} \mathrm{O}$ 1.46, $\mathrm{KH}_{2} \mathrm{PO}_{4} 1.2, \mathrm{MgSO}_{4}$ 1.2, d-glucose 11.1, and $\mathrm{NaHCO}_{3}$ 25), $\mathrm{pH} 7.4$, maintained at $37^{\circ} \mathrm{C}$ under a resting tension of $1 \mathrm{~g}$, and continuously aerated with $95 \% \mathrm{O}_{2}$ and $5 \% \mathrm{CO}_{2}$. Tension changes were obtained through isometric transducers coupled to DATAQ Instruments data acquisition hardware connected to a computer with specific software integration (WinDaq software, DATAQ Instruments, Akron, Ohio, USA). The rings remained at an equilibrium period of $60 \mathrm{~min}$, with solution changes every $15 \mathrm{~min}$. Then, the preparations were contracted with a potassium chloride solution $(\mathrm{KCl}: 60 \mathrm{mM})$ to test their responsiveness. To confirm the presence of a functional endothelium, a further $30 \mathrm{~min}$ stabilization period was expected. A new contraction was induced by adding phenylephrine $(\mathrm{PE}: 1 \mu \mathrm{M})$, followed by administering $1 \mu \mathrm{M}$ acetylcholine $(\mathrm{ACh})$. Only rings that showed relaxation equal to or greater than $80 \%$ were considered with functional endothelium. For preparations devoid of endothelium, this was mechanically removed by gently scraping the endothelial cells away from the intima. A new 30 min interval was expected for stabilization, and the aortic rings were then exposed to cumulative concentrations of EAF (10 to $500 \mu \mathrm{g}$ / $\mathrm{mL}$ ) in preparations with and without functional endothelium at the plateau of the PE-induced contraction. To study the mechanisms involved in the vasorelaxant effect induced by the EAF, the rings were preincubated $(30 \mathrm{~min})$ before the addition of $\mathrm{PE}$, with the following drugs: L-NAME $(100 \mu \mathrm{M}$, a nonselective NO synthase inhibitor), ODQ $(100 \mu \mathrm{M}$, an inhibitor of soluble guanylyl cyclase), atropine $(1 \mu \mathrm{M}$, a muscarinic receptor antagonist), indomethacin $(1 \mu \mathrm{M}$, a cyclooxygenase inhibitor), and with the $\mathrm{K}^{+}$channel blockers, which are as follows: tetraethylammonium (TEA, $1 \mathrm{mM}$, a calcium-activated $\mathrm{K}^{+}$channel blocker) or TEA $\left(10 \mathrm{mM}\right.$, a nonselective $\mathrm{K}^{+}$channel blocker), glibenclamide $\left(10 \mu \mathrm{M}\right.$, an ATP-sensitive $\mathrm{K}^{+}$ channel blocker), 4-aminopyridine (4-AP, $1 \mathrm{mM}$, a voltagesensitive $\mathrm{K}^{+}$channel blocker), or barium chloride $\left(\mathrm{BaCl}_{2}\right.$, $10 \mu \mathrm{M}$, a nonselective inward-rectifier $\mathrm{K}^{+}$channel blocker). The cumulative concentration curve of EAF was obtained in the presence of these drugs or just the vehicle.

2.6. Blood Pressure Analysis. The blood pressure study was conducted, as previously described by Da Silva et al. [18]. After anesthesia with ketamine/xylazine $(80 / 10 \mathrm{mg} / \mathrm{kg}$; by intramuscular route), the left femoral vein was cannulated with a polyethylene catheter filled with physiological saline solution $(0.9 \%)$ for administration of heparin to prevent clot formation. The left carotid artery was isolated from the vagus nerve for insertion of a polyethylene catheter, which was connected to a pressure transducer coupled to an AECAD 04P recording system, running the software AQCAD 2.3.7 (Bonther, Ribeirão Preto, Brazil). Blood pressure was stabilized for $15 \mathrm{~min}$ with continuous real-time blood pressure recording. After that, three doses of $\operatorname{EAF}(0.3,1$, and $3 \mathrm{mg} /$ $\mathrm{kg})$, acetylcholine $(10 \mathrm{nmol} / \mathrm{kg})$, or vehicle were administered to the rats. All doses were given in a $200 \mu \mathrm{L}$ bolus through duodenal access. Changes in mean arterial pressure (MAP), systolic arterial pressure (SAP), diastolic arterial pressure (DAP), and heart rate (HR) were recorded and compared between groups.

2.7. Statistical Analysis. All data are expressed as the mean\pm standard error of the mean (SEM) from six preparations or animals per group. One- or two-way analysis of variance (ANOVA) followed by Bonferroni's multiple comparison test was performed using GraphPad Prism version 8 for Windows (GraphPad Software, La Jolla, CA, USA). A pvalue less than 0.05 was considered statistically significant.

\section{Results}

3.1. Chemical Analyses by LC-DAD-MS. The EAF was analyzed by LC-DAD-MS, and twenty-one compounds were annotated (Table 1 and Figure 1). The compounds were annotated based on their spectral data (MS, MS/MS, and UV) compared with data reported in the literature, and standards were used to confirm some compounds when possible.

The peaks 1 and $\mathbf{2}$ were putatively annotated as di-Ohexoside and shikimic acid, while the compounds $\mathbf{3}, \mathbf{5}$, and $\mathbf{6}$ presented similar UV spectra, and from the accurate mass, their molecular formulas were determined as $\mathrm{C}_{7} \mathrm{H}_{6} \mathrm{O}_{5}$, $\mathrm{C}_{8} \mathrm{H}_{8} \mathrm{O}_{5}$, and $\mathrm{C}_{15} \mathrm{H}_{14} \mathrm{O}_{6}$. In addition, 5 also revealed the product ion at $m / z 168\left[\mathrm{M}-\mathrm{H}^{-}{ }^{\bullet} \mathrm{CH}_{3}\right]^{-\bullet}{ }^{19}$, suggesting a methoxyl group, and 3 and $\mathbf{6}$ were confirmed by the authentic standard. Thus, 3, 5, and $\mathbf{6}$ were annotated as gallic acid, methyl gallate, and catechin.

The peaks 4, 7, and 8 showed similar UV $\left(\lambda_{\max } \approx 275 \mathrm{~nm}\right)$, and they revealed a molecular formula with high number of carbons such as $\mathrm{C}_{41} \mathrm{H}_{26} \mathrm{O}_{26}$. They revealed fragment ions at $m / z 301$ and 169 which are relative to ellagic acid, confirming the hexahydroxydiphenoyl (HHDP) and gallic acid (Singh et al., 2016). For example, the successive losses of galloyl $(152 u)$ from $m / z 635$ [M-H $]^{-}(8)$ yielded the fragment ions $m / z 465\left[\mathrm{M}-\mathrm{H}-152-\mathrm{H}_{2} \mathrm{O}\right]^{-}$and 313 [M-H-152$\left.2 \mathrm{xH}_{2} \mathrm{O}\right]^{-}$. The compounds 4,7 , and $\mathbf{8}$ were annotated as the hydrolysable tannins castalagin isomer, acutissimin A or B, and tri-O-galloyl hexoside, respectively.

The peaks $\mathbf{1 1}$ and $\mathbf{1 6}$ revealed the absorption bands in the UV spectra at the wavelength $\approx 280$ and $368 \mathrm{~nm}$, which is compatible with the chromophore of ellagic acid. The compound $11\left(\mathrm{~m} / z 300.9996[\mathrm{M}-\mathrm{H}]^{-}, \mathrm{C}_{14} \mathrm{H}_{6} \mathrm{O}_{8}\right)$ was confirmed by ellagic acid as the authentic standard. The protonated ion from 16 revealed losses of $15 u(\mathrm{~m} / z 330[\mathrm{M}+\mathrm{H}-$ $\left.{ }^{\circ} \mathrm{CH}_{3}\right]^{+\bullet}$ and $315\left[\mathrm{M}+\mathrm{H}-2 \mathrm{x}^{\bullet} \mathrm{CH}_{3}\right]^{+\bullet}$ ), suggesting the methoxyl substituents [19], so it was annotated as tri-Omethyl ellagic acid.

The compounds 9-10, 12-13, 15, and 17-19 revealed spectral data compatible to dihydrochalcones, such as the UV data. The characteristics of losses of 180 (hexosyl $+\mathrm{H}_{2} \mathrm{O}$ molecules) and 152 (galloyl), $42 u$ (cetene) and subsequent losses of 90 and $120 u$ suggest the substituents $O$-hexosyl, galloyl, acetyl, and $C$-hexosyl [20-23]. They were annotated as $O$-hexosyl phloretin (9), C-hexosyl hydroxyphlorizin (10), di-C-hexosyl phloretin (12), $C$-hexosyl phloretin (nothofagin) (13), $C$-hexosyl phloretin (15), O-galloyl $C$-hexosyl 
TABle 1: Chemical constituents from the ethyl acetate fraction (EAF) of L. dasytricha.

\begin{tabular}{|c|c|c|c|c|c|c|c|}
\hline \multirow{2}{*}{ Peak } & \multirow{2}{*}{ Compound } & \multirow{2}{*}{$\mathrm{RT}(\min )$} & \multirow{2}{*}{ MF } & \multirow{2}{*}{$\mathrm{UV}(\mathrm{nm})$} & \multicolumn{2}{|c|}{$m / z$} & \multirow{2}{*}{ MS/MS } \\
\hline & & & & & {$[\mathrm{M}+\mathrm{H}]^{+}$} & {$[\mathrm{M}-\mathrm{H}]^{-}$} & \\
\hline 1 & Di-O-hexoside & 1.1 & $\mathrm{C}_{12} \mathrm{H}_{22} \mathrm{O}_{11}$ & - & $365.1044^{\mathrm{Na}}$ & 341.1028 & - \\
\hline 2 & Shikimic acid & 1.2 & $\mathrm{C}_{7} \mathrm{H}_{10} \mathrm{O}_{5}$ & - & - & 173.0459 & - \\
\hline 3 & Gallic acid st $^{\text {st }}$ & 2.4 & $\mathrm{C}_{7} \mathrm{H}_{6} \mathrm{O}_{5}$ & 270 & - & 169.0125 & - \\
\hline 4 & Castalagin isomer & 4.5 & $\mathrm{C}_{41} \mathrm{H}_{26} \mathrm{O}_{26}$ & 285 & 935.0803 & $466.0275^{-2}$ & $466 \longrightarrow 301,275,231,191,169$ \\
\hline 5 & Methyl gallate & 7.8 & $\mathrm{C}_{8} \mathrm{H}_{8} \mathrm{O}_{5}$ & 270 & 185.0444 & 183.0299 & $183 \longrightarrow 168$ \\
\hline 6 & Catechin $^{\text {st }}$ & 9.1 & $\mathrm{C}_{15} \mathrm{H}_{14} \mathrm{O}_{6}$ & 270 & 291.0855 & 289.0695 & $289 \longrightarrow 221,203,151$ \\
\hline 7 & Acutissimin $\mathrm{A} / \mathrm{B}$ isomer & 9.7 & $\mathrm{C}_{56} \mathrm{H}_{38} \mathrm{O}_{31}$ & 285 & - & $602.0626^{-2}$ & $602 \longrightarrow 467,301,275,249,169$ \\
\hline 8 & Tri-O-galloyl hexoside & 15.6 & $\mathrm{C}_{27} \mathrm{H}_{24} \mathrm{O}_{18}$ & 270 & 637.1035 & 635.089 & $635 \longrightarrow 465,313,423,271,211,169$ \\
\hline 9 & O-hexosyl phloretin & 16.0 & $\mathrm{C}_{21} \mathrm{H}_{24} \mathrm{O}_{10}$ & 284 & 437.1442 & 435.1297 & $435 \longrightarrow 255,229$ \\
\hline 10 & C-hexosyl hydroxyphlorizin & 16.6 & $\mathrm{C}_{21} \mathrm{H}_{24} \mathrm{O}_{11}$ & 284 & 453.1391 & 451.1246 & $451 \longrightarrow 361,331,239,167$ \\
\hline 11 & Ellagic acid ${ }^{\text {st }}$ & 17.7 & $\mathrm{C}_{14} \mathrm{H}_{6} \mathrm{O}_{8}$ & 282,368 & 303.0120 & 300.9996 & $301 \longrightarrow 283,257,245,229$ \\
\hline 12 & Di-C-hexosyl phloretin & 19.1 & $\mathrm{C}_{27} \mathrm{H}_{34} \mathrm{O}_{15}$ & 286 & 599.1970 & 597.1825 & $597 \longrightarrow 417,387,357,315,209,167$ \\
\hline 13 & C-hexosyl phloretin (nothofagin) & 19.4 & $\mathrm{C}_{21} \mathrm{H}_{24} \mathrm{O}_{10}$ & 286 & 437.1442 & 435.1297 & $435 \longrightarrow 345,315,273,209,167$ \\
\hline 14 & Unknown & 20.8 & $\mathrm{C}_{27} \mathrm{H}_{28} \mathrm{O}_{12}$ & 280 & 545.1654 & 543.1508 & $543 \longrightarrow 313,229,169$ \\
\hline 15 & C-hexosyl phloretin & 24.2 & $\mathrm{C}_{21} \mathrm{H}_{24} \mathrm{O}_{10}$ & 285 & 437.1437 & 435.1293 & $435 \longrightarrow 345,315,272,209,179,167$ \\
\hline 16 & Tri-O-methyl ellagic acid & 24.4 & $\mathrm{C}_{17} \mathrm{H}_{12} \mathrm{O}_{8}$ & 285,368 & 345.0605 & 343.0459 & $345 \longrightarrow 330,315,285$ \\
\hline 17 & O-galloyl C-hexosyl phloretin & 24.8 & $\mathrm{C}_{28} \mathrm{H}_{28} \mathrm{O}_{14}$ & 284 & 589.1536 & 587.1412 & $587 \longrightarrow 345,315,273,209,167$ \\
\hline 18 & $O$-acetyl $C$-hexosyl phloretin & 25.6 & $\mathrm{C}_{23} \mathrm{H}_{26} \mathrm{O}_{11}$ & 284 & 479.1525 & 477.1407 & $477 \longrightarrow 345,315,273,167$ \\
\hline 19 & Phloretin & 28.4 & $\mathrm{C}_{15} \mathrm{H}_{14} \mathrm{O}_{5}$ & 285 & 275.0914 & 273.0768 & $273 \longrightarrow 189,167,151$ \\
\hline 20 & Triterpene & 33.8 & $\mathrm{C}_{30} \mathrm{H}_{48} \mathrm{O}_{5}$ & - & 489.3575 & 487.3429 & - \\
\hline 21 & Triterpene & 34.6 & $\mathrm{C}_{30} \mathrm{H}_{48} \mathrm{O}_{5}$ & - & 489.3564 & 487.3445 & - \\
\hline
\end{tabular}

MF: molecular formula; RT: retention time; ${ }^{\mathrm{Na}}:[\mathrm{M}+\mathrm{Na}]^{+} ;{ }^{-2}:[\mathrm{M}-2 \mathrm{H}]^{-2}$; st: confirmed by authentic standard.

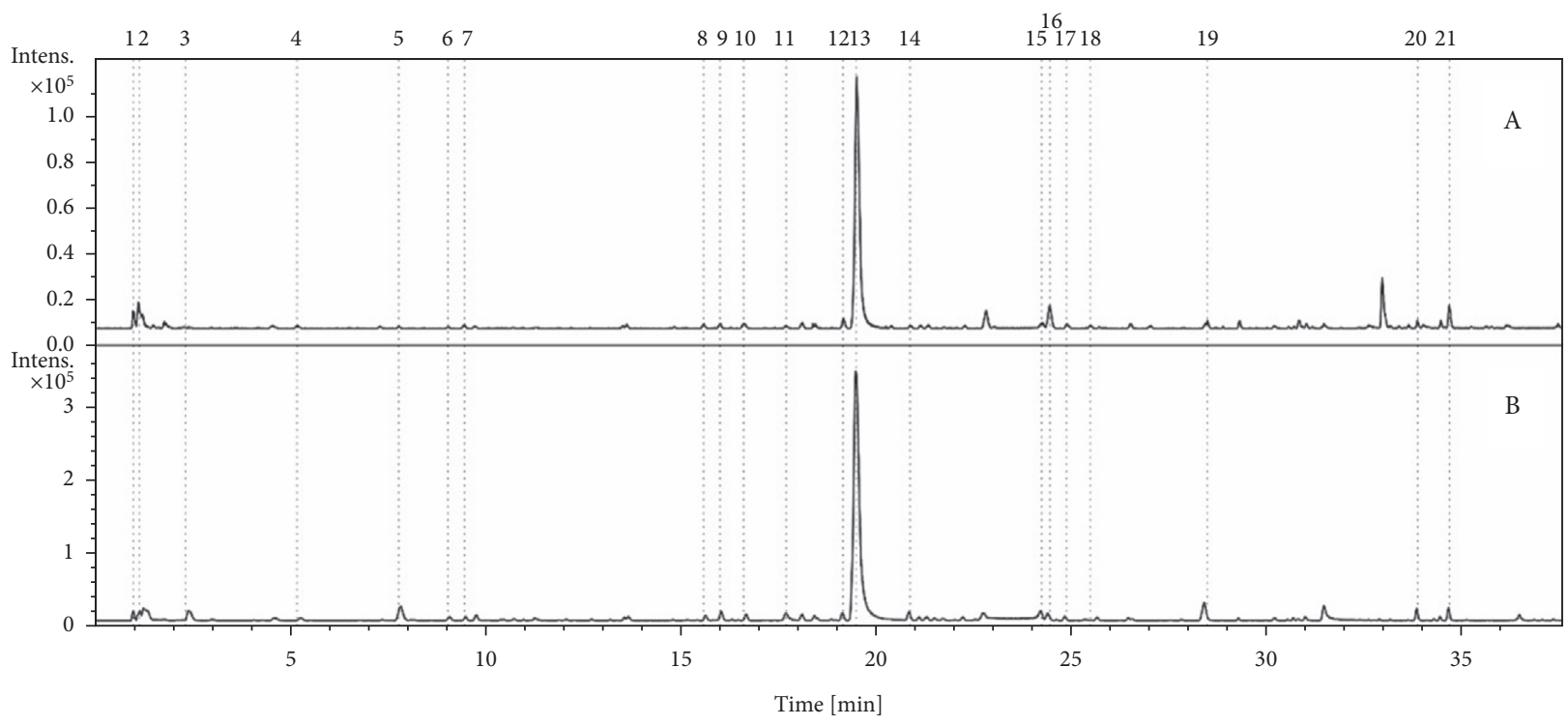

FIgURE 1: Base peak chromatograms obtained in positive (a) and negative ion mode (b) chromatograms from EAF.

phloretin (17), O-acetyl C-hexosyl phloretin (18), and phloretin (19). The molecular structure of the major peak identified in the ethyl acetate fraction from L. dasytricha, nothofagin (13), can be seen in Figure S1 (supplementary material).

3.2. Effect of EAF from L. dasytricha in Thoracic Aorta Rings Precontracted with Phenylephrine. The cumulative addition of EAF caused a concentration-dependent vasorelaxant effect in the endothelium intact aortic rings of both NTRs and SHRs. The maximal relaxation $\left(R_{\max }\right)$ values in endothelium intact preparations were $83.22 \pm 9.05 \%$ in NTRs and $74.87 \pm 7.30 \%$ in SHRs (Figures 2(a) and 2(b), respectively). The vasodilator effect in the endothelium-denuded aorta was only $27.07 \pm 16.54 \%$ in NTRs and $16.80 \pm 8.09 \%$ in SHRs, indicating that the endothelium is essential for the relaxation induced by EAF. The vehicle (Krebs solution), represented in all images by the closed rectangle symbol, did not affect the aortic rings tonus.

3.3. Involvement of Nitric Oxide in the Vasorelaxant Activity of $E A F$. The nonselective nitric oxide synthase inhibitor 


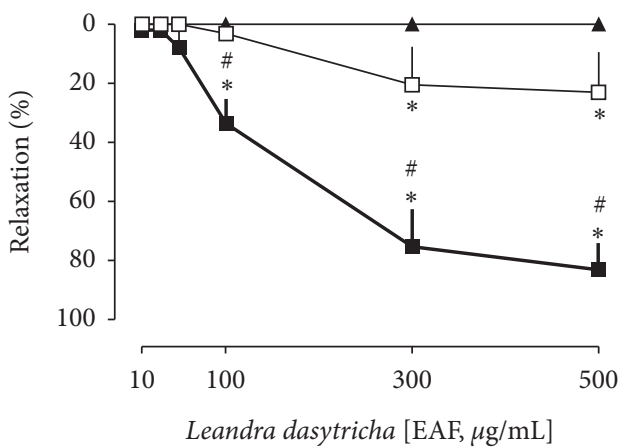

NTR

$\Delta$ Vehicle

$\square$ E-

- E+

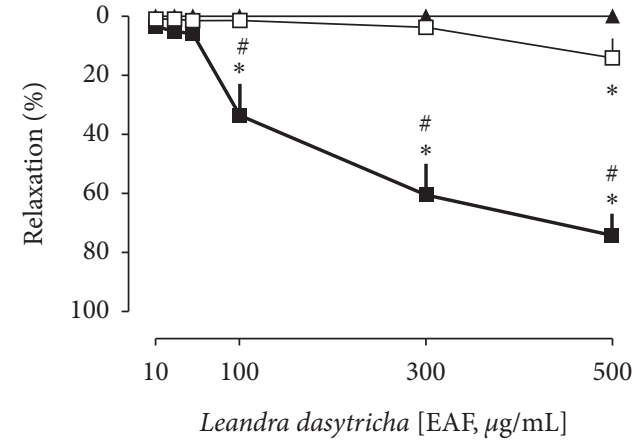

SHR
A Vehicle
$\square$ E-
- E+

(a)

(b)

FIGURE 2: Vasorelaxation induced by EAF in the aorta of Wistar normotensive rats (NTRs) and spontaneously hypertensive rats (SHRs). Concentration-response curves were determined in endothelium-intact (E+) or endothelium-denuded (E-) rings. (a) The EAF-induced vasorelaxation in the NTR aorta. (b) EAF-induced vasorelaxation in the SHR aorta. Statistical analyses were performed using a two-way analysis of variance followed by Bonferroni's multiple comparison test. ${ }^{*} p<0.05$ when compared to the vehicle (closed triangles), and ${ }^{\#} p<0.05$ when compared to E- (opened squares).

L-NAME, as well as the soluble guanylate cyclase inhibitor ODQ, entirely blocked the EAF-induced relaxation in both NTR and SHR aorta rings (Figure 3). Besides, it can be seen in Figure 4 that neither atropine nor indomethacin modified the EAF-induced vasodilation response in the aorta of NTRs and SHRs.

\subsection{Effect of $\mathrm{K}^{+}$Channel Blockers on EAF-Induced Relaxation.} The EAF-induced relaxation was significantly reduced in the presence of the nonselective potassium channel blocker (TEA, $10 \mathrm{mM}$ ) in both NTR and SHR preparations (Figures 5(a) and 5(b), respectively). Besides, TEA at a concentration of $1 \mathrm{mM}$ (Figures 5(c) and 5(d)), which acts as a $\mathrm{Ca}^{2+}$-activated $\mathrm{K}^{+}$channel blocker, reduced the relaxation response of EAF in both NTR and SHR aortas. The preincubation with 4-aminopyridine (4-AP), a voltage-dependent $\mathrm{K}^{+}$channel blocker, significantly interfered with the EAF's relaxation in both NTR and SHR preparations (Figures 6(a) and 6(b), respectively). However, the incubation with glibenclamide $(10 \mu \mathrm{M})$, an ATP-sensitive $\mathrm{K}^{+}$ channel blocker, and barium chloride $(10 \mu \mathrm{M})$, an inwardrectifier $\mathrm{K}^{+}$channel blocker, did not interfere with the EAFinduced relaxation (Figures 6(c)-6(f)).

\subsection{EAF Reduces Mean and Systolic Blood Pressure in Both} Normotensive and Hypertensive Rats. As depicted in Table 2, the EAF treatment at doses of 1 and $3 \mathrm{mg} / \mathrm{kg}$, but not $0.3 \mathrm{mg} /$ $\mathrm{kg}$, triggered a dose-dependent decrease in the blood pressure of NTRs, with a reduction of $\sim 24 \mathrm{~mm} \mathrm{Hg}$ (at the highest dose tested) in the values of MAP, SAP, and DAP. Regarding the EAF treatment in SHR, a dose-dependent decrease in the blood pressure was also observed, with a reduction of $\sim 21 \mathrm{~mm} \mathrm{Hg}$ in the values of MAP, SAP, and $\mathrm{DAP}$ at the highest dose tested. The values obtained with the administration of acetylcholine $(10 \mathrm{nmol} / \mathrm{kg})$ are also shown in Table 2 as the positive control of the experiment. None of the treatments significantly interfered with heart rate values (data not shown).

\section{Discussion}

In the present study, we showed that a semipurified fraction obtained from the leaves of Leandra dasytricha (A. Gray) Cong. induced a concentration-dependent relaxation in the aorta preparations, as well as dose-dependent hypotensive and antihypertensive effects in NTRs and SHRs, respectively. Due to the similarity with human arterial hypertension pathogenesis, SHRs have become the animals of choice for screening antihypertensive agents $[15,24]$; thus, our study evidences a meaningful fraction-mediated action in an established disease model with translation into clinical practice.

The analyses by LC-DAD-MS from EAF revealed several compounds that had not been reported previously in L. dasytricha; thus, we here expanded the chemical knowledge of this medicinal species. Between the compounds annotated, we highlighted hydrolysable tannins, triterpenes, and mainly dihydrochalcones, such as the most intense ion peak C-hexosyl phloretin (nothofagin). This dihydrochalcone has been reported as a diuretic and natriuretic with potassium-sparing effects $[11,12]$.

The EAF-induced vasorelaxation was blunted with the endothelium removal, indicating that the integrity of the 


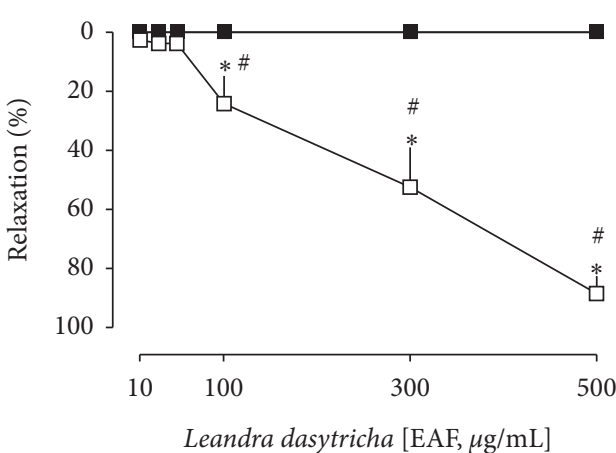

NTR

A Vehicle

$\square+$ Vehicle

口 + L-NAME $(100 \mu \mathrm{M})$

(a)

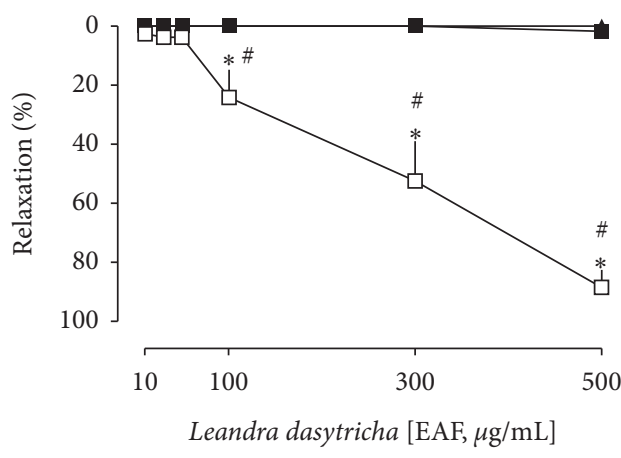

NTR

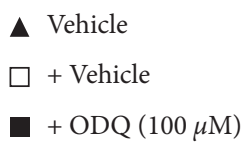

(c)

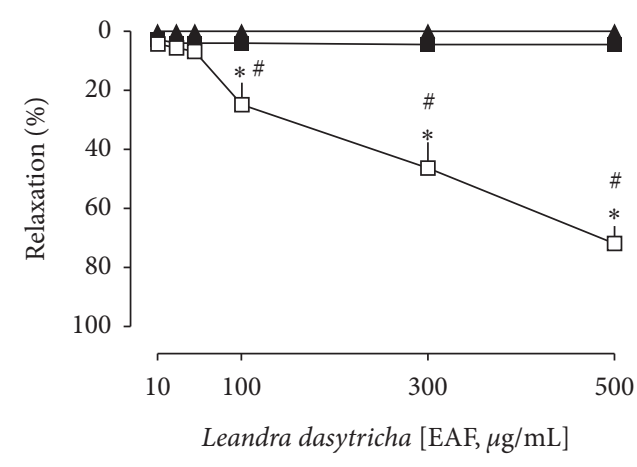

SHR

$\Delta$ Vehicle

$\square+$ Vehicle

- + L-NAME $(100 \mu \mathrm{M})$

(b)

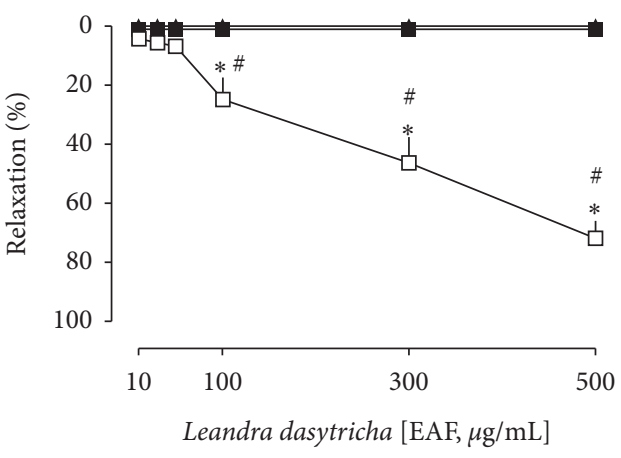

SHR

$$
\begin{aligned}
& \Delta \text { Vehicle } \\
& \square+\text { Vehicle } \\
& \text { घ + ODQ }(100 \mu \mathrm{M})
\end{aligned}
$$

(d)

FIgURE 3: Vasorelaxation induced by EAF in the aorta of Wistar normotensive rats (NTRs) and spontaneously hypertensive rats (SHRs) in the absence or presence of L-NAME $(\mathrm{a}, \mathrm{b})$ and ODQ $(\mathrm{c}, \mathrm{d})$. Statistical analyses were performed using a two-way analysis of variance followed by Bonferroni's multiple comparison test. ${ }^{*} p<0.05$ when compared to the vehicle (closed triangles), and ${ }^{\#} p<0.05$ when compared to the vehicle-only incubation (opened squares).

endothelium is necessary to EAF's vasodilation. To investigate the mechanism of endothelium-dependent relaxation, the vessels were pretreated with L-NAME, which completely blocked the vasorelaxation response, indicating NO's participation in the vasodilator response produced by EAF. Endothelial cells may cause vasorelaxation by releasing vasoactive substances called endothelium-derived relaxing factor (EDRF), identified as NO [25]. NO production and release is mediated through the upregulation of the endothelium nitric oxide synthase (eNOS) activity. NO diffuses into the vascular smooth muscle cells where it stimulates the soluble guanylate cyclase (sGC) that increases cyclic guanosine monophosphate (cGMP) concentration, which in turn activates a GMP-dependent protein kinase (PKG) that can phosphorylate and inhibit the myosin light chain kinase
(MLCK), reducing myosin phosphorylation and consequently promoting vascular smooth muscle relaxation $[26,27]$. The selective inhibitor of the sGC enzyme ODQ also inhibited the EAF-induced vasorelaxation. These results confirm the involvement of the NO/cGMP pathway in the EAF-induced endothelium-dependent relaxation.

In addition to $\mathrm{NO}$ production through the muscarinic receptor, endothelium cells can also induce relaxation by releasing prostaglandin $\mathrm{I}_{2}\left(\mathrm{PGI}_{2}\right.$, prostacyclin) through the cyclooxygenase pathway. $\mathrm{PGI}_{2}$ activates the prostaglandin I2 receptor, or just IP receptor, on the vascular smooth muscle cell membrane, coupled to adenylate cyclase through the protein (Gs), promoting an increase in cyclic adenosine monophosphate (cAMP) levels. cAMP levels have been a key cellular event to trigger blood vessel 


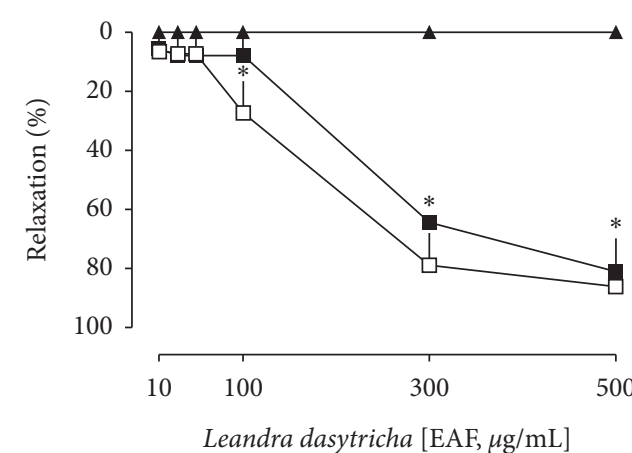

NTR
- Vehicle
$\square+$ Vehicle
+ Atropine $(1 \mu \mathrm{M})$

(a)

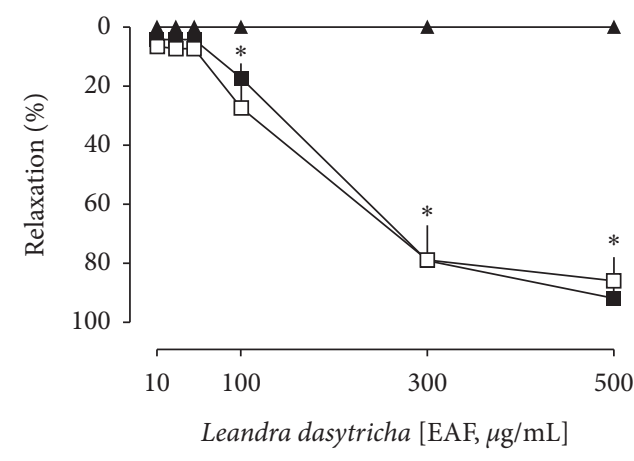

NTR

$\boldsymbol{\Delta}$ Vehicle
$\square+$ Vehicle
$\boldsymbol{\square}+$ Indomethacin $(1 \mu \mathrm{M})$

(c)

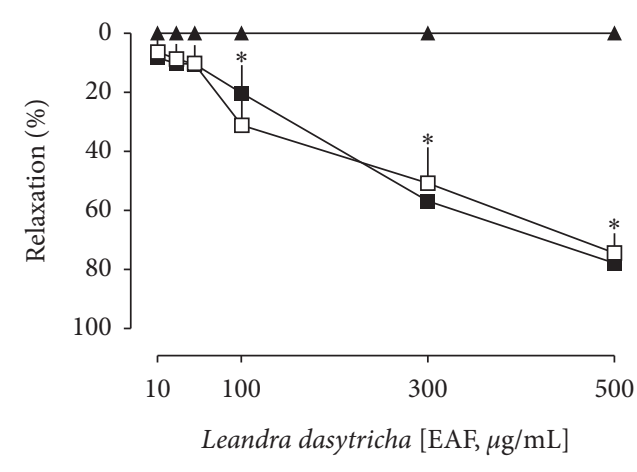

SHR
A Vehicle
$\square+$ Vehicle
+ Atropine $(1 \mu \mathrm{M})$

(b)

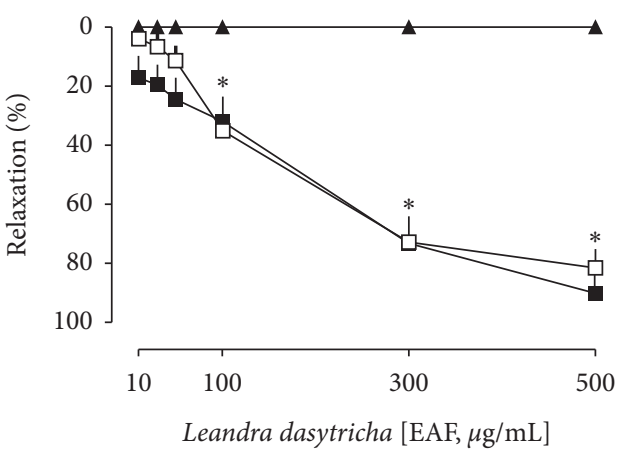

SHR
$\Delta$ Vehicle
$\square+$ Vehicle
- Indomethacin $(1 \mu \mathrm{M})$

(d)

FIgURE 4: Vasorelaxation induced by EAF in the aorta of Wistar normotensive rats (NTRs) and spontaneously hypertensive rats (SHRs) in the absence or presence of atropine $(a, b)$ and indomethacin $(c, d)$. Statistical analyses were performed using a two-way analysis of variance followed by Bonferroni's multiple comparison test. ${ }^{*} p<0.05$ when compared to the vehicle (closed triangles).

relaxation by IP agonists [25]. Increased concentrations of cGMP or cAMP are correlated with smooth muscle relaxation induced by various drugs and phytochemicals $[28,29]$. However, neither the muscarinic receptor antagonism nor the cyclooxygenase inhibition was able to modify the EAF-induced vasodilation, suggesting that these pathways are not pivotal for the relaxant effect of this fraction.

The second pathway of PKG stimulation is the activation of the $\mathrm{K}^{+}$channel [30]. The opening of a $\mathrm{K}^{+}$channel in the vascular smooth muscle membrane cells causes hyperpolarization, increasing $\mathrm{K}^{+}$efflux, leading to the closure of $\mathrm{Ca}^{2+}$ channels and, consequently, vasodilation [31]. TEA, at high concentrations, is a nonspecific $\mathrm{K}^{+}$channel blocker that inhibits the ATP-, voltage-, and calcium-dependent subtypes of channels. Our results showed that the presence of TEA $(10 \mathrm{mM})$ produced a significant reduction in the aortic relaxant response induced by the EAF, indicating the participation of $\mathrm{K}^{+}$channels. Many subtypes of $\mathrm{K}^{+}$channels have been identified in smooth muscle cells [32]. The contribution of each channel to vasodilation is estimated from the effect of selective inhibitors. Glibenclamide, which acts as a selective blocker of adenosine triphosphate- (ATP-) dependent $\mathrm{K}^{+}$channels, and barium chloride, a selective blocker of inward-rectifier $\mathrm{K}^{+}$channels, did not modify the EAF-induced relaxation, indicating that these $\mathrm{K}^{+}$channel subtypes are not the main ones responsible for the fraction's actions. On the other hand, TEA $(1 \mathrm{mM})$, which acts as a large-conductance $\mathrm{Ca}^{2+}$-activated $\mathrm{K}^{+}$channel blocker, and 4-AP, a selective voltage-dependent $\mathrm{K}^{+}$channel blocker, 


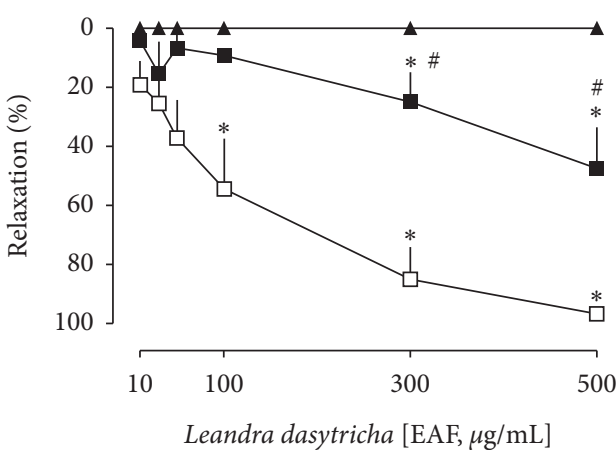

NTR

A Vehicle

$\square+$ Vehicle

+ TEA $(10 \mathrm{mM})$

(a)

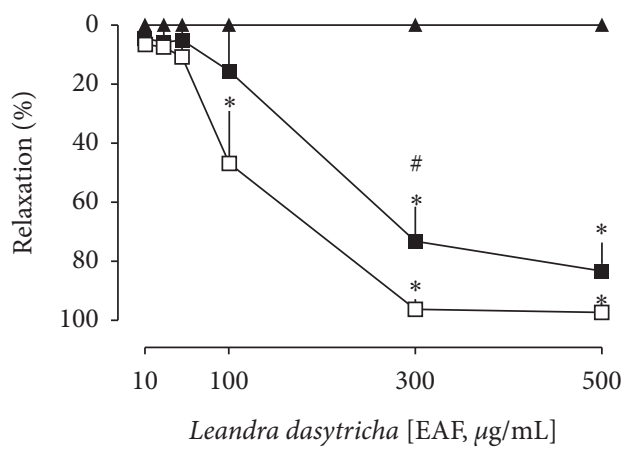

NTR

A Vehicle

$\square+$ Vehicle

+ TEA $(1 \mathrm{mM})$

(c)

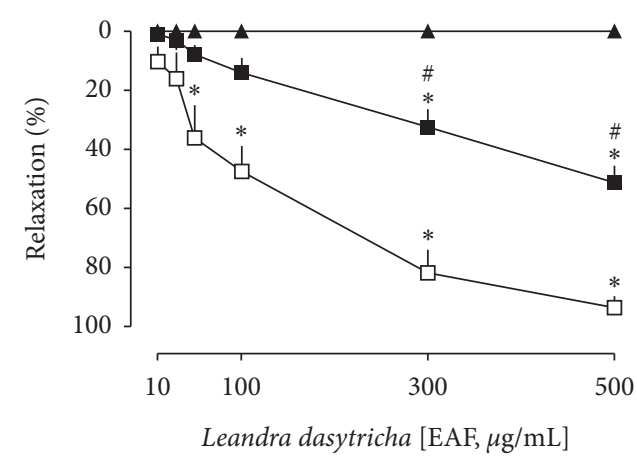

SHR

$\Delta$ Vehicle

$\square+$ Vehicle

- TEA $(10 \mathrm{mM})$

(b)

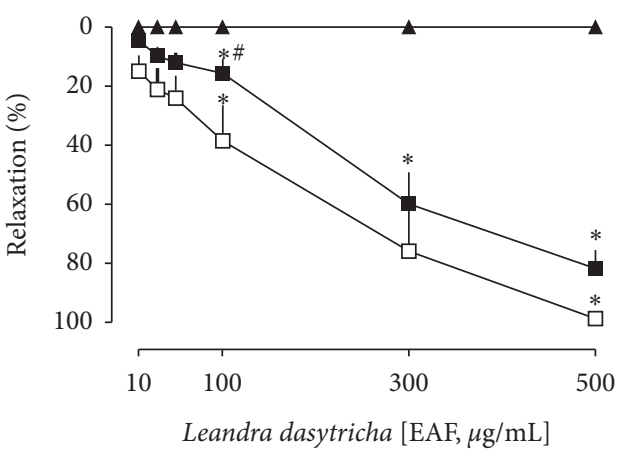

SHR

$\boldsymbol{\Delta}$ Vehicle
$\square+$ Vehicle
$\boldsymbol{\square}+$ TEA $(1 \mathrm{mM})$

(d)

FIgURE 5: Vasorelaxation induced by EAF in the aorta of Wistar normotensive rats (NTRs) and spontaneously hypertensive rats (SHRs) in the absence or presence of TEA $10 \mathrm{mM}(\mathrm{a}, \mathrm{b})$ and TEA $1 \mathrm{mM}(\mathrm{c}, \mathrm{d})$. Statistical analyses were performed using a two-way analysis of variance followed by Bonferroni's multiple comparison test. ${ }^{*} p<0.05$ when compared to the vehicle (closed triangles), and ${ }^{\#} p<0.05$ when compared to the vehicle-only incubation (opened squares).

significantly reduced the vasorelaxation response of EAF. The voltage-dependent $\mathrm{K}^{+}$channels are activated by depolarizing the membrane potential, resulting in repolarization and a return to the resting membrane potential, maintaining the resting vascular tone. The $\mathrm{Ca}^{2+}$-activated $\mathrm{K}^{+}$channels are activated by either increased intracellular $\mathrm{Ca}^{2+}$ or membrane depolarization, resulting in the control of $\mathrm{Ca}^{2+}$ influx and $\mathrm{K}^{+}$efflux [33]. Indeed, these subtypes of $\mathrm{K}^{+}$channels seem to be the main ones for the fraction's vasodilating actions.

Our results suggest that EAF has bioactive compounds, which induce endothelium-dependent vasodilation, mainly through the NO pathway with consequent activation of $\mathrm{K}^{+}$ channels. The isolated rat aorta model has been a valuable tool to validate the vasoactive properties of extracts and compounds obtained from plants [34]. Extending these findings to the in vivo system, it was interesting to evaluate the effect of the EAF on the blood pressure values of rats. The data presented herein revealed that the treatment with EAF reduced the MAP, SAP, and DAP of both normotensive and hypertensive animals. In SHR, hypertension is generally attributed to the increased activity of the sympathetic nervous system, hyperactivation of the renin-angiotensin-aldosterone system, and endothelial dysfunction mainly due to the reduced bioavailability of $\mathrm{NO}[35,36]$. Thus, strategies aimed at reestablishing some of these pathways are essential tools for the therapeutic management of hypertension and associated conditions. 


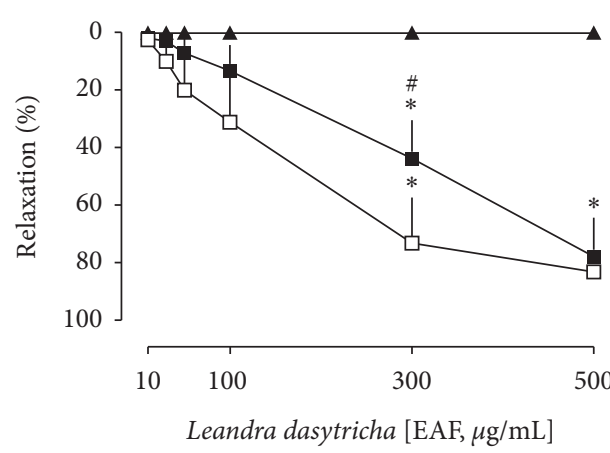

NTR

A Vehicle

$\square+$ Vehicle

+4-AP (1 mM)

(a)

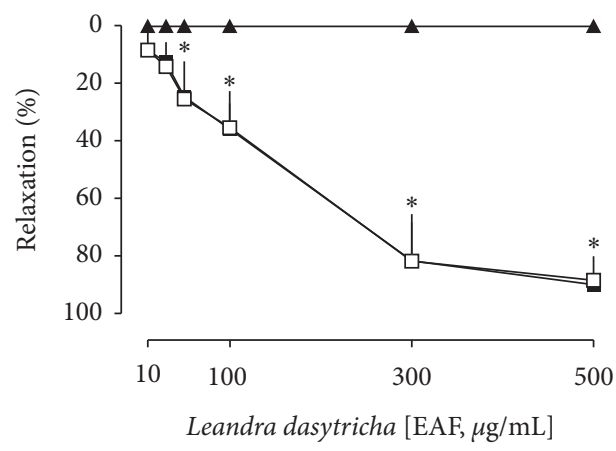

NTR

\ Vehicle

$\square+$ Vehicle

- + GLI $(10 \mu \mathrm{M})$

(c)

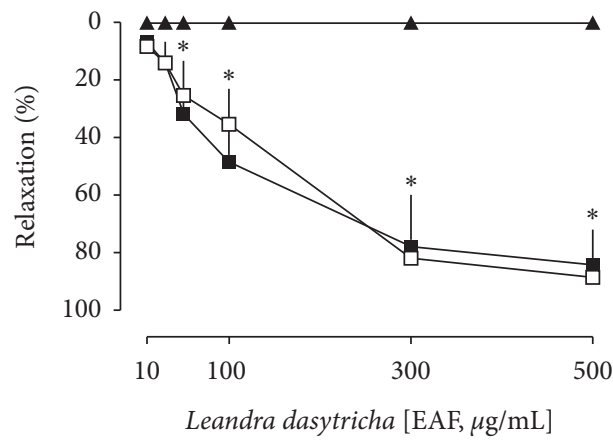

NTR

$\Delta$ Vehicle

$\square+$ Vehicle

$+\operatorname{BaCl} 2(10 \mu \mathrm{M})$

(e)

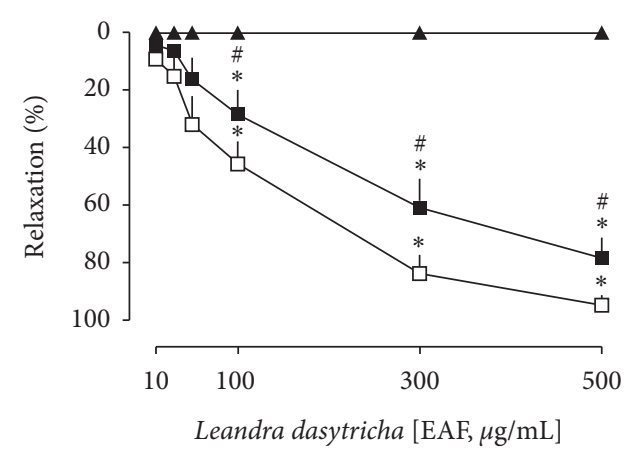

SHR

\ Vehicle

$\square+$ Vehicle

- +4-AP $(1 \mathrm{mM})$

(b)

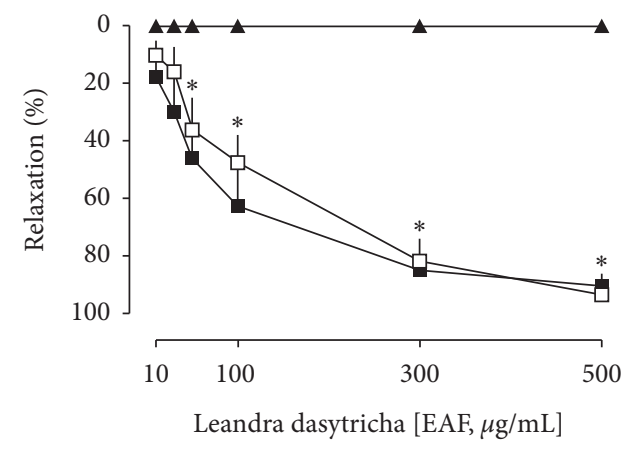

SHR

$\Delta$ Vehicle

$\square+$ Vehicle

- + GLI $(10 \mu \mathrm{M})$

(d)

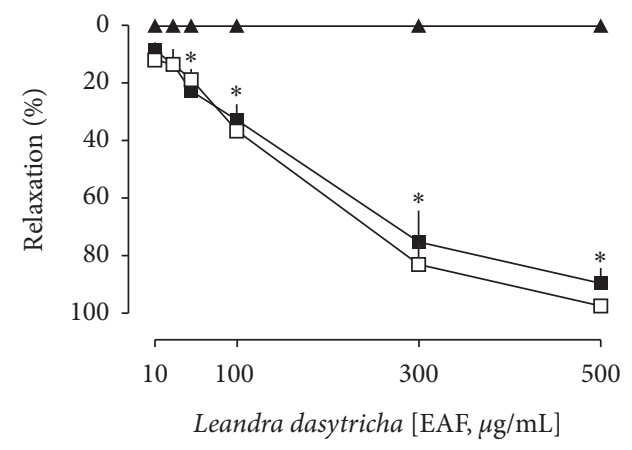

SHR

$\Delta$ Vehicle

$\square+$ Vehicle

- $+\operatorname{BaCl} 2(10 \mu \mathrm{M})$

(f)

FIGURE 6: Vasorelaxation induced by EAF in the aorta of Wistar normotensive rats (NTRs) and spontaneously hypertensive rats (SHRs) in the absence or presence of 4-AP (a,b), glibenclamide (c, d), and $\mathrm{BaCl}_{2}(\mathrm{e}$, and $\mathrm{f})$. Statistical analyses were performed using a two-way analysis of variance followed by Bonferroni's multiple comparison test. ${ }^{*} p<0.05$ when compared to the vehicle (closed triangles), and ${ }^{\#} p<0.05$ when compared to the vehicle-only incubation (opened squares). 
TABLE 2: Effects of EAF (0.3, 1, and $3 \mathrm{mg} / \mathrm{kg}$ ) treatment on the blood pressure of normotensive rats (NTRs) and hypertensive rats (SHRs).

\begin{tabular}{|c|c|c|c|c|c|}
\hline Groups & Vehicle & Acetylcholine $10 \mathrm{nmol} / \mathrm{kg}$ & EAF $0.3 \mathrm{mg} / \mathrm{kg}$ & EAF $1 \mathrm{mg} / \mathrm{kg}$ & EAF $3 \mathrm{mg} / \mathrm{kg}$ \\
\hline \multicolumn{6}{|c|}{ NTR } \\
\hline MAP (mm Hg) & - & $-12.82 \pm 3.07^{*}$ & $-4.07 \pm 1.99$ & $-11.78 \pm 3.55^{* \#}$ & $-24.20 \pm 2.45^{* \#}$ \\
\hline SAP (mm Hg) & - & $-12.44 \pm 4.03^{*}$ & $-3.47 \pm 2.21$ & $-12.20 \pm 3.56^{* \#}$ & $-24.22 \pm 2.30^{* \#}$ \\
\hline DAP (mm Hg) & - & $-13.71 \pm 2.03^{*}$ & $-2.08 \pm 1.49$ & $-14.08 \pm 3.94^{* \#}$ & $-25.36 \pm 2.77^{* \#}$ \\
\hline \multicolumn{6}{|c|}{ SHR } \\
\hline MAP (mm Hg) & - & $-20.75 \pm 6.86^{*}$ & $-2.92 \pm 1.68$ & $-10.71 \pm 2.32^{* \#}$ & $-21.17 \pm 2.46^{* \#}$ \\
\hline $\mathrm{SAP}(\mathrm{mm} \mathrm{Hg})$ & - & $-20.92 \pm 5.45^{*}$ & $-4.09 \pm 1.93$ & $-10.70 \pm 2.67^{* \#}$ & $-21.37 \pm 3.29^{* \#}$ \\
\hline $\mathrm{DAP}(\mathrm{mm} \mathrm{Hg})$ & - & $-21.76 \pm 6.69^{*}$ & $-4.46 \pm 1.33$ & $-11.19 \pm 1.75^{* \#}$ & $-21.35 \pm 1.93^{* \#}$ \\
\hline
\end{tabular}

The results show the mean \pm S.E.M. of 6 animals in each group. Statistical analyses were performed by means of a one-way analysis of variance followed by Bonferroni's multiple comparison test. ${ }^{*} p<0.05$ when compared to a vehicle, and ${ }^{\#} p<0.05$ when compared to EAF $0.3 \mathrm{mg} / \mathrm{kg}$ or EAF $1 \mathrm{mg} / \mathrm{kg}$. MAP, mean arterial pressure; SAP, systolic arterial pressure; and DAP, diastolic arterial pressure.

\section{Conclusions}

The present study shows that a semipurified fraction obtained from the Leandra dasytricha leaves has bioactive compounds that can synergistically induce vascular relaxation and, consequently, reduce blood pressure in normotensive and hypertensive animals. Further studies are required to confirm the mechanisms of action suggested in this study, which point to the involvement of the NO/cGMP pathway and $\mathrm{K}^{+}$channel activation.

\section{Abbreviations}

$\begin{array}{ll}\text { ACh: } & \text { Acetylcholine } \\ \text { AHA: } & \text { American Heart Association } \\ \text { 4-AP: } & \text { 4-Aminopyridine } \\ \text { BaCl }_{2}: & \text { Barium chloride } \\ \text { CVD: } & \text { Cardiovascular disease } \\ \text { cGMP: } & \text { Cyclic guanosine monophosphate } \\ \text { cAMP: } & \text { Cyclic adenosine monophosphate } \\ \text { DAP: } & \text { Diastolic arterial pressure } \\ \text { eNOS: } & \text { Endothelium nitric oxide synthase } \\ \text { EDRF: } & \text { Endothelium-derived relaxing factor } \\ \text { GLI: } & \text { Glibenclamide } \\ \text { PKG: } & \text { GMP-dependent protein kinase } \\ \text { ODQ: } & \text { H-[1,2,3]oxadiazolo[4,3-alpha]quinoxalin } \\ \text { HR: } & \text { Heart rate } \\ \text { MAP: } & \text { Mean arterial pressure } \\ \text { MLCK: } & \text { Myosin light-chain kinase } \\ \text { NO: } & \text { Nitric oxide } \\ \text { L-NAME: } & \text { N } \omega \text {-nitro-l-arginine methyl ester } \\ \text { NTR: } & \text { Normotensive rat } \\ \text { PE: } & \text { Phenylephrine } \\ \text { PGI }: & \text { Prostaglandin I } \\ \text { SAP: } & \text { Systolic arterial pressure } \\ \text { sGC: } & \text { Soluble guanylate cyclase } \\ \text { SHR: } & \text { Spontaneously hypertensive rat } \\ \text { EAF: } & \text { Ethyl acetate fraction } \\ \text { TEA: } & \text { Tetraethylammonium. } \\ & \end{array}$

\section{Data Availability}

Data are available from the corresponding author on request.

\section{Conflicts of Interest}

The authors declare no conflicts of interest.

\section{Authors' Contributions}

R.C.V. da Silva and P. de Souza wrote the manuscript. The phytochemical procedures and analysis were carried out by C.L.B. Almeida, V. Cechinel-Filho, A. Gasparotto-Junior, V.S.S. Zanuncio, and D.B. Silva. Pharmacological assays were idealized and undertaken by E.R. Bidinha, L.N.B. Mariano, R.C.V. da Silva, and P. de Souza. All authors reviewed and approved the final version of the manuscript.

\section{Acknowledgments}

This study was supported by the Conselho Nacional de Desenvolvimento Científico e Tecnológico, Coordenação de Aperfeiçoamento de Pessoal de Nível Superior, Fundação de Amparo à Pesquisa e Inovação do Estado de Santa Catarina, and Universidade do Vale do Itajaí. Dr. Rita de Cássia Vilhena da Silva is grateful for the postdoctoral scholarship and financial support from PNPD/CAPES.

\section{Supplementary Materials}

Figure S1: molecular structure of nothofagin (13) identified in the ethyl acetate fraction from L. dasytricha. (Supplementary Materials)

\section{References}

[1] American Heart Association, AHA: Heart Disease Remains Leading Cause of Death Worldwide; Trends Discouraging, American Heart Association, Dallas, TX, USA, 2021, https://www.healio.com/news/cardiology/20210127/ahaheart-disease-remains-leading-cause-of-death-worldwide-trendsdiscouraging.

[2] P. C. W. van den Hoogen, "The relation between blood pressure and mortality due to coronary heart disease among men in different parts of the world," New England Journal of Medicine, vol. 342, pp. 1-81, 2000.

[3] A. V. Chobanian, G. L. Bakris, H. R. Black et al., "Seventh report of the joint national committee on prevention, detection, evaluation, and treatment of high blood pressure," Hypertension, vol. 42, pp. 1206-1252, 2003. 
[4] B. Williams, G. Mancia, W. Spiering et al., "ESC/ESH Guidelines for themanagement of arterial hypertension," European Heart Journal, vol. 39, pp. 3021-3104, 2018.

[5] M. G. Saklayen and N. V. Deshpande, "Timeline of history of hypertension treatment," Frontiers in Cardiovascular Medicine, vol. 3, 2016.

[6] C. Cuspidi, M. Tadic, G. Grassi, and G. Mancia, "Treatment of hypertension: the ESH/ESC guidelines recommendations," Pharmacological Research, vol. 128, pp. 315-321, 2018.

[7] WHO, WHO Traditional Medicine Strategy: 2014-2023, WHO, Geneva, Switzerland, 2015.

[8] M. Sobral, J. A. Jarenkow, P. Brack, B. E. Irgang, J. Larocca, and R. S. Rodrigues, Flora Arbórea e Arborescente do rio Grande do Sul, RiMa Editora, São Paulo, Brazil, 1 edition, 2006.

[9] W. R. Cunha, G. M. Arantes, D. S. Ferreira et al., "Hypoglicemic effect of Leandra lacunosa in normal and alloxaninduced diabetic rats," Fitoterapia, vol. 79, pp. 356-360, 2008.

[10] Q. Zhang, H. N. ElSohly, X. C. Li, and L. A. Walker, "A new triterpene from Leandra chaetodon," Planta Medica, vol. 69, pp. 582-584, 2003.

[11] C. L. B. de Almeida, T. Boeing, L. Bordignon Somensi et al., "Diuretic, natriuretic and potassium-sparing effect of nothofagin isolated from Leandra dasytricha (A. Gray) Cogn. leaves in normotensive and hypertensive rats," Chemico-Biological Interactions, vol. 268, pp. 103-110, 2017.

[12] C. L. B. de Almeida, V. Cechinel-Filho, T. Boeing et al., "Prolonged diuretic and saluretic effect of nothofagin isolated from Leandra dasytricha (A. Gray) Cogn. leaves in normotensive and hypertensive rats: role of antioxidant system and renal protection," Chemico-Biological Interactions, vol. 279, pp. 227-233, 2018.

[13] A. A. M. Marques, C. Henrique Francisconi da Silva, P. de Souza et al., "Nitric oxide and Ca2+-activated highconductance $\mathrm{K}+$ channels mediate nothofagin-induced endothelium-dependent vasodilation in the perfused rat kidney," Chemico-Biological Interactions, vol. 327, 2020.

[14] K. Okamoto and K. Aoki, "Development of a strain of spontaneously hypertensive rats," Japanese Circulation Journal, vol. 27, pp. 282-293, 1963.

[15] N. C. Trippodo and E. D. Frohlich, "Similarities of genetic (spontaneous) hypertension. Man and rat," Circulation Research, vol. 48, pp. 309-319, 1981.

[16] S. E. L. Tolouei, C. Adriane Signor Tirloni, R. Alan Calloi Palozi et al., "Celosia argentea L. (Amaranthaceae) a vasodilator species from the Brazilian Cerrado-An ethnopharmacological report," Journal of Ethnopharmacology, vol. 229, pp. 115-126, 2019.

[17] R. Da Silva, S. Crestani, P. de Souza et al., "Endotheliumdependent and independent vasorelaxation induced by an n-butanolic fraction of bark of Scutia buxifolia Reiss (Rhamanaceae)," Journal of Ethnopharmacology, vol. 141, pp. 997-1004, 2012.

[18] R. Da Silva, P. de Souza, S. Crestani et al., "Hypotensive and diuretic effect of the butanolic soluble fraction of the hydroethanolic extract of bark of Scutia buxifolia Reissek in rats," Journal of Ethnopharmacology, vol. 172, pp. 395-401, 2015.

[19] A. M. Mustafa, S. Angeloni, D. Abouelenein et al., "A new HPLC-MS/MS method for the simultaneous determination of 36 polyphenols in blueberry, strawberry and their commercial products and determination of antioxidant activity," Food Chemistry, vol. 367, Article ID 130743, 2022.

[20] Z. Fan, Y. Wang, M. Yang, J. Cao, A. Khan, and G. Cheng, "UHPLC-ESI-HRMS/MS analysis on phenolic compositions of different E Se tea extracts and their antioxidant and cytoprotective activities," Food Chemistry, vol. 318, Article ID 126512, 2020.

[21] I. M. Abu-Reidah, D. Arráez-Román, I. Warad, A. FernándezGutiérrez, and A. Segura-Carretero, "UHPLC/MS2-based approach for the comprehensive metabolite profiling of bean (Vicia faba L.) by-products: a promising source of bioactive constituents," Food Research International, vol. 93, pp. 87-96, 2017.

[22] M. F. Mahomoodally, S. Jugreet, K. I. Sinan et al., "Pharmacological potential and chemical characterization of Bridelia ferruginea benth. - a native tropical african medicinal plant," Antibiotics, vol. 10, no. 2, p. 223, 2021.

[23] G. Baeza, B. Sarriá, L. Bravo, and R. Mateos, "Exhaustive qualitative LC-DAD-MSn analysis of arabica green coffee beans: cinnamoyl-glycosides and cinnamoylshikimic acids as new polyphenols in green coffee," Journal of Agricultural and Food Chemistry, vol. 64, no. 51, pp. 9663-9674, 2016.

[24] A. Singh, V. Bajpai, S. Kumar, K. R. Sharma, and B. Kumara, "Profiling of gallic and ellagic acid derivatives in different plant parts of Terminalia arjuna by HPLC-ESI-QTOF-MS/MS," Natural Products Communications, vol. 11, pp. 239-244, 2016.

[25] G. Gendron, F. Gobeil, J. Morin, P. D’Orléans-Juste, and D. Regoli, "Contractile responses of aortae from WKY and SHR to vasoconstrictors," Clinical and Experimental Hypertension, vol. 26, pp. 511-523, 2004.

[26] M. Félétou, R. Köhler, and P. M. Vanhoutte, "Nitric oxide: orchestrator of endothelium-dependent responses," Annals of Medicine, vol. 44, pp. 694-716, 2012.

[27] R. M. J. Palmer, A. G. Ferrige, and S. Moncada, "Nitric oxide release accounts for the biological activity of endotheliumderived relaxing factor," Nature, vol. 327, pp. 524-526, 1987.

[28] P. M. Vanhoutte, H. Shimokawa, M. Feletou, and E. H. C. Tang, "Endothelial dysfunction and vascular disease-a thirthieth anniversary update," Acta Physiologica, vol. 219, 2015.

[29] F. Murad, "Cyclic guanosine monophosphate as a mediator of vasodilation," Journal of Clinical Investigation, vol. 78, pp. 1-5, 1986.

[30] M. Knox, R. Vinet, L. Fuentes, B. Morales, and J. L. Martínez, "A review of endothelium-dependent and -independent vasodilation induced by phytochemicals in isolated rat aorta," Animals, vol. 9, p. 623, 2019.

[31] S. L. Archer, J. M. Huang, V. Hampl, D. P. Nelson, P. J. Shultz, and E. K. Weir, "Nitric oxide and cGMP cause vasorelaxation by activation of a charybdotoxin-sensitive $\mathrm{K}$ channel by cGMP-dependent protein kinase," Proceedings of the National Academy of Sciences of the United States of America, vol. 91, pp. 7583-7587, 1994.

[32] M. T. Nelson and J. M. Quayle, "Physiological roles and properties of potassium channels in arterial smooth muscle," American Journal of Physiology, vol. 268, pp. C799-C822, 1995.

[33] N. B. Standen and J. M. Quayle, " $\mathrm{K}^{+}$channel modulation in arterial smooth muscle," Acta Physiologica Scandinavica, vol. 164, pp. 549-557, 1998.

[34] M. Rameshrad, H. Babaei, Y. Azarmi, and R. F. Fouladi, "Rat aorta as a pharmacological tool for in vitro and in vivo studies," Life Sciences, vol. 145, pp. 190-204, 2016.

[35] R. J. Head, "Hypernoradrenergic innervation: its relationship to functional and hyperplastic changes in the vasculature of the spontaneously hypertensive rat," Blood Vessels, vol. 26, pp. 1-20, 1989.

[36] J. de Champlain, "Pre- and postsynaptic adrenergic dysfunctions in hypertension," Journal of Hypertension-Supplement, vol. 8, 1990. 